\title{
OCELOT (LEOPARDUS PARDALIS): AN ADDITION TO THE MAMMALS OF CHIHUAHUA, MEXICO
}

\author{
Carlos A. López González,2, Cristian Aguilar Miguel ${ }^{1}$, \\ Federico Mora Carrilloํㄹ and Zaira Y. González ${ }^{1}$
}

\begin{abstract}
We present the first documented record of an ocelot (Leopardus pardalis) for the Mexican state of Chihuahua. The animal was camera-trapped in open oak woodland. This finding increases the number of mammal species present in the northern Sierra Madre Occidental and reinforces the need for continuing surveys in the barrancas region of Chihuahua.
\end{abstract}

REsumen.-Documentamos el primer registro de ocelote (Leopardus pardalis) para el Estado de Chihuahua, Mexico asociado a un bosque abierto de encinos, incrementando el numero de species presente en el norte de la Sierra Madre Occidental, fortaleciendo la necesidad de continuar la búsqueda de estas especies en la región de las barrancas.

The ocelot (Leopardus pardalis) is a mediumsized neotropical felid that is traditionally associated with tropical environments (Caso et al. 2008). It is considered the most common neotropical felid in Mexico and has a known distribution encompassing the Mexican Pacific coastal states from northern Sonora into Central America and areas along the Gulf coast from southern Texas to the border of Guatemala (Caso et al. 2008). With the advent of recent technological advances, namely camera trapping, new distributional records for the ocelot have been documented in Mexico, such as those for Aguascalientes (Valdez-Jiménez et al. 2013) and Guanajuato (Iglesias et al 2008). We report the first record of an ocelot for the state of Chihuahua, Mexico.

In 2013, during multiple camera-trap surveys to assess mammalian diversity in the Sierra Madre Occidental of Chihuahua, we documented the presence of a male ocelot from 3 cameras over a period of 12 days. The first documented event took place on 21 September at 03:39 (UTM: zone 13, $759111 \mathrm{~N}, 3373228 \mathrm{E}$ ); the second event took place on 3 October at 03:34 (UTM: zone 13, 763051 N, 3372503 E); and the last event occurred on 12 October at 01:08 (UTM: zone 13, 759949 N, 3374308 E) (Fig. 1).

Although we obtained pictures of both a left and a right side of an ocelot, the photographs are not simultaneous and do not have sufficient clarity to determine if they represent the same individual. Distances between events ranged from 1.21 to $4.91 \mathrm{~km}$; such movement likely represents the same individual. The records are located approximately $35 \mathrm{~km} \mathrm{~W}$ of the city of Nuevo Casas Grandes. The habitat in the area is dominated by open oak woodlands and native grasslands. The records were documented at an average elevation of $1973 \mathrm{~m}( \pm 180 \mathrm{~m})$, which is considered high elevation for the species (Moreno Arzate et al. 2011).

Known breeding populations of ocelots are present in the state of Sonora, approximately $110 \mathrm{~km} \mathrm{SE}$ of the Chihuahuan records (Fig. 2) (López González et al. 2003). There are additional male ocelot records for the state of Sonora (170 km ENE) and Arizona, USA (224 $\mathrm{km}$ ENE), but no reproduction has been documented at those sites (Holbrook et al. 2011, Avila-Villegas and Lamberton-Moreno 2012). Ocelots typically disperse 10-15 km (Ludlow and Sunquist 1987, Laack 1991), with $50 \mathrm{~km}$ from the original capture site being the longest dispersal distance documented for a male ocelot (Booth-Binczik 2007). Dispersal distances for ocelots in marginal habitats most likely increase as habitats become fragmented and open. So it would not be surprising to have one or more ocelots disperse from a possible source population that is $110 \mathrm{~km}$ or more from Sonora (López González et al. 2003).

\footnotetext{
${ }^{1}$ Universidad Autónoma de Querétaro, Cerro de las Campanas S/N, Col. Las Campanas, Queretaro, Qro. C.P. 76010.

2E-mail: cats4mex@gmail.com
} 


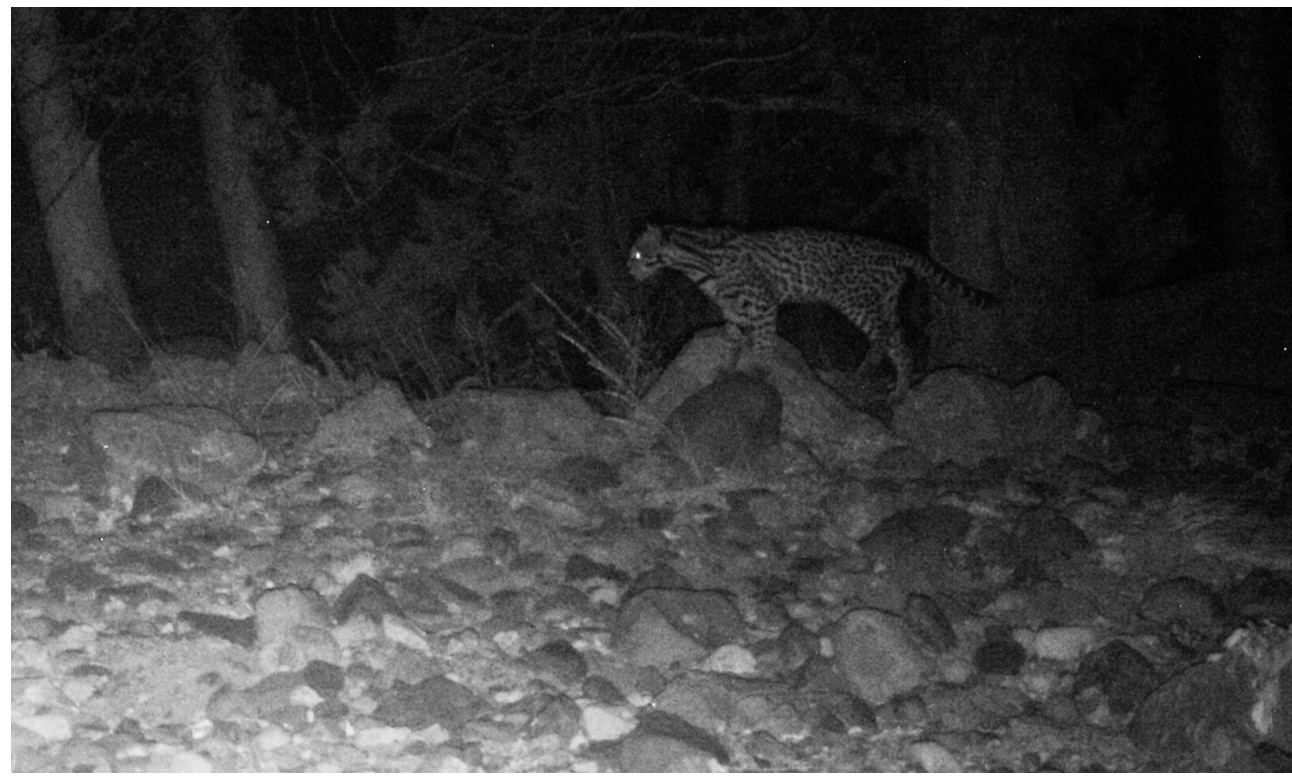

WILDVIEW 10-12-2013 01:08:44

Fig. 1. Ocelot (Leopardus pardalis) camera-trap photograph taken in northwestern Chihuahua.
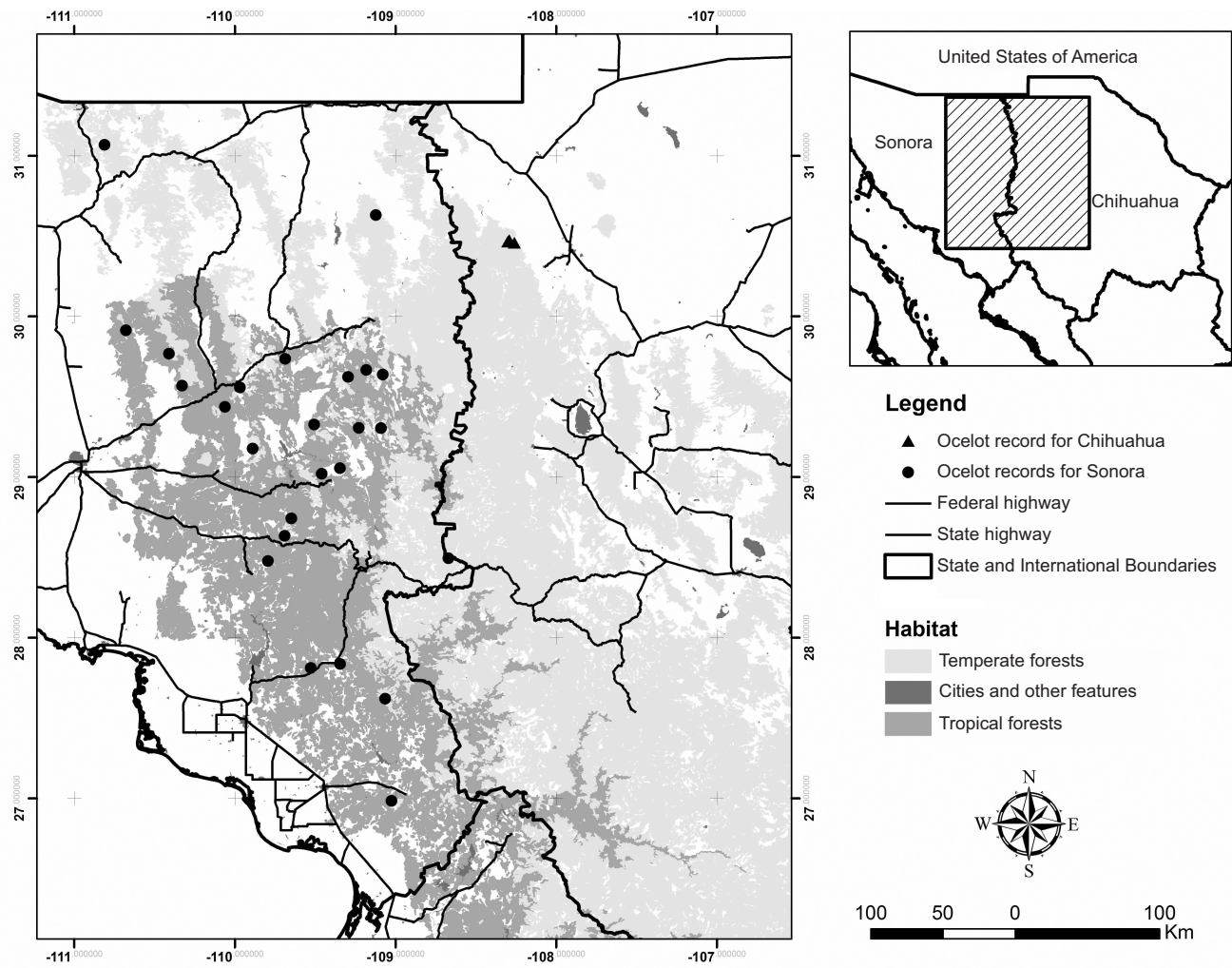

Legend

- Ocelot record for Chihuahua

- Ocelot records for Sonora

_ Federal highway

- State highway

State and International Boundaries

Habitat

Temperate forests

Cities and other features

Tropical forests
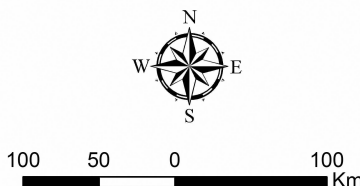

Fig. 2. Geographic location of the ocelot records for Chihuahua in relation to tropical forests and ocelot records in Sonora, Mexico. 
Anderson (1972) and López González and García-Mendoza (2012) have proposed the existence of ocelots in Chihuahua based on the presence of tropical habitats, which are mainly in the southern portion of the state. Our record validates the assumed presence of the species for the state; however, our record is associated with temperate biomes that are relatively far from the tropical habitats present in the state. This observation reinforces the need to continue and expand the documentation of mammal occurrences in the barrancas region of Chihuahua. Further documentation will likely reveal small but resilient populations of ocelots and other mammalian species that are currently vulnerable in other parts of their ranges.

We thank the several ranch owners who allowed us to survey their lands. Additional field support was provided by university technicians. CONANP provided financial support through the project Monitoreo y manejo de la población reintroducida de lobo Mexicano (PROCER/DGOR/02/2013).

\section{Literature Cited}

Anderson, S. 1972. Mammals of Chihuahua: taxonomy and distribution. Bulletin of the American Museum of Natural History 148:149-410.

Avila-Villegas, S., and J.A. Lamberton-Moreno. 2012. Wildlife survey and monitoring in the Sky Island region with an emphasis on neotropical felids. Pages 1-5 in G.J. Gottfried, P.F. Ffolliott, B.S. Gebow, L.G. Eskew, and L.C. Collins, compilers, Merging science and management in a rapidly changing world: biodiversity and management of the Madrean Archipelago III and 7th Conference on Research and Resource Management in the Southwestern Deserts.
Booth-Binczik, S.D. 2007. Report from the field: monitoring ocelot dispersal with satellite telemetry. Endangered Species Update 24:110-112.

Caso, A., C. López-González, E. Payan, E. Eizirik, T. de Oliveira, R. Leite-Pitman, M. Kelly, and C. VALDERRAma. 2008. Leopardus pardalis. The IUCN Red List of Threatened Species. Version 2014.2. [Accessed 11 August 2014]. Available from: http:// www.iucnredlist.org

Holbrook, J.D., R.W. DeYoung, M.E. Tewes, J.H. Young, J.L. MAYs, AND E. MeYers. 2011. Natural dispersal or illegal pets? Limitations on assigning origin to roadkilled ocelots in the southwestern United States. Wildlife Society Bulletin 35:504-507.

Iglesias, J., V. Sánchez-Cordero, G. Magaña-Cota, R. Bolaños, M. Aranda, R. Hernández, and F.J. BOTELLO. 2008. Noteworthy records of margay, Leopardus wiedii and ocelot, Leopardus pardalis in the state of Guanajuato, Mexico. Mammalia 72: 347-349.

LAACK, L.L. 1991. Ecology of the ocelot (Felis pardalis) in south Texas. Master's thesis, Texas A\&I University, Kingsville, TX.

López GonZÁLEZ, C., AND D.F. García-Mendoza. 2012. A checklist of the mammals (Mammalia) of Chihuahua, Mexico. Check List 8:1122-1133.

López GonZÁlez, C.A., D.E. Brown, and J.P. GaLloReynoso. 2003. The ocelot Leopardus pardalis in north-western Mexico: ecology, distribution and conservation status. Oryx 37:358-364.

LudLow, M.E., AND M.E. SunQuist. 1987. Ecology and behavior of ocelots in Venezuela. National Geographic Research 3:447-461.

Moreno Arzate, E., L.I.I. Dávalos, and C.A.L. GonZÁlez. 2011. High elevation records of ocelots (Leopardus pardalis) in Jalisco, Mexico. Mammalia 75:387-388.

Valdez-Jiménez, D., C.M. García-Balderas, and G.E. Quintero-Díaz. 2013. Presencia del ocelote (Leopardus pardalis) en la "Sierra del Laurel", Municipio de Calvillo, Aguascalientes, México. Acta Zoológica Mexicana 29:688-692.

Received 24 September 2014 Accepted 30 September 2014 